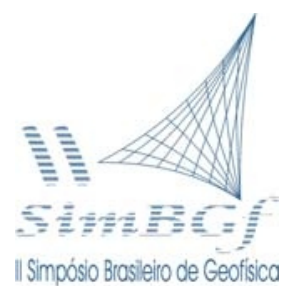

21 a 23 de Setembro de 2006, Natal - RN

\title{
Atividade Símica de Bebedouro (SP) Induzida por Poços Tubulares
}

Marcelo Assumpção ${ }^{1}$, Tereza H. Yamabe ${ }^{2}$, José Roberto Barbosa ${ }^{1}$, Afonso E. V.lopes ${ }^{1}$, e Lucas Balancin ${ }^{1}$ 1 IAG/USP marcelo@iag.usp.br, 2 FCT/UNESP-PP higashi@fct.unesp.br

Copyright 2006, SBGf-Sociedade Brasileira de Geofísica

Este texto foi preparado para a apresentação no Il Simpósio de Geofísica da Sociedade Brasileira de Geofísica, Natal, 21-23 de setembro de 2006. Seu conteúdo foi revisado pela Comissão Tecno-científica do II SR-SBGf mas não necessariamente representa a pela Comissão Tecno-cientifica do II SR-SBGf mas não necessariamente representa a material para propósitos comerciais sem prévia autorização da SBGf

\section{Resumo}

Três enxames de tremores de terra já ocorreram em Bebedouro, Nordeste do Estado de São Paulo. O primeiro foi sentido de janeiro a julho de 2004 e o segundo, de dezembro de 2004 a abril de 2005. Estações sismográficas instaladas em março de 2005 registraram centenas de sismos com magnitudes de até 2,9. Os epicentros estão localizados nas proximidades de poços tubulares de $120-200 \mathrm{~m}$ de profundidade que exploram aqüíferos fraturados no basalto. Os tremores ocorrem quando esses poços não são bombeados. O terceiro surto de atividade iniciou-se em abril de 2006, com epicentros dentro da Fazenda Aparecida onde quatro novos poços haviam sido perfurados um mês antes.

\section{Introdução}

Tremores de terra têm ocorrido no Distrito de Andes, Bebedouro, nordeste do Estado de São Paulo. Os eventos são sentidos principalmente em propriedades rurais de Andes, em uma área aproximada de $50 \mathrm{~km}^{2}$. Os primeiros eventos foram sentidos a partir de janeiro de 2004. Desde então, períodos de baixa e alta atividade sísmica vêm se alternando correspondendo a períodos de menor e maior índices de chuva, respectivamente. Nos meses de pouca chuva os poços tubulares próximos aos epicentros são bombeados continuamente para irrigação de plantações de laranja, período em que a atividade sísmica diminui. Segundo informações dos proprietários dos poços, na época de irrigação o bombeamento é quase contínuo durante meses, geralmente entre agosto e dezembro.

A pedido da Prefeitura de Bebedouro, o Instituto de Astronomia, Geofísica e Ciências Atmosféricas (IAG/USP) mantém, desde março de 2005, uma rede de sismógrafos para estudar essa atividade sísmica.

Nos períodos de maior atividade sísmica as estações sismográficas de Andes têm registrado um número bastante alto de tremores, em alguns dias as contagens ultrapassam 100 a 200 eventos, dos quais cerca de 20 a 30 sentidos pelos moradores da área epicentral. Em geral os mais fortes fazem as casas 'balançarem', cachorros saem latindo, chão e venezianas vibram muito, quadros pendurados se deslocam e as pessoas saem correndo de dentro das casas. Há também relatos, não confirmados, de trincas em paredes e piso de varanda. Alguns sismos de magnitudes maiores, de até 2,9, foram também registrados pela Estação Sismográfica de Rio Claro,
$180 \mathrm{~km}$ a SE de Bebedouro, operada pela UNESP. A Fig. 1 mostra a localização das estações sismográficas, dos epicentros dos sismos maiores ocorridos em 2005 e dos poços que perfuraram o basalto.

Até o segundo enxame de sismos, a proximidade dos epicentros com os poços e as ocorrências cíclicas dos tremores eram fortes indícios da relação entre a atividade sísmica e a perfuração/bombeamento dos poços usados para irrigação de cítricos.

Para contribuir com os estudos sismológicos, foram realizadas perfilagens geofísicas de poço, incluindo a térmica, gama e BHTV, (Yamabe et al., neste Simpósio). Estes estudos mostraram que os poços profundos de Bebedouro agem como condutos que transportam água do aquífero superior (arenito) para o aquífero fraturado no basalto, e ajudaram a compreender o possível mecanismo de indução da sismicidade pelos poços profundos.

\section{Area de Estudos, Andes, Bebedouro}

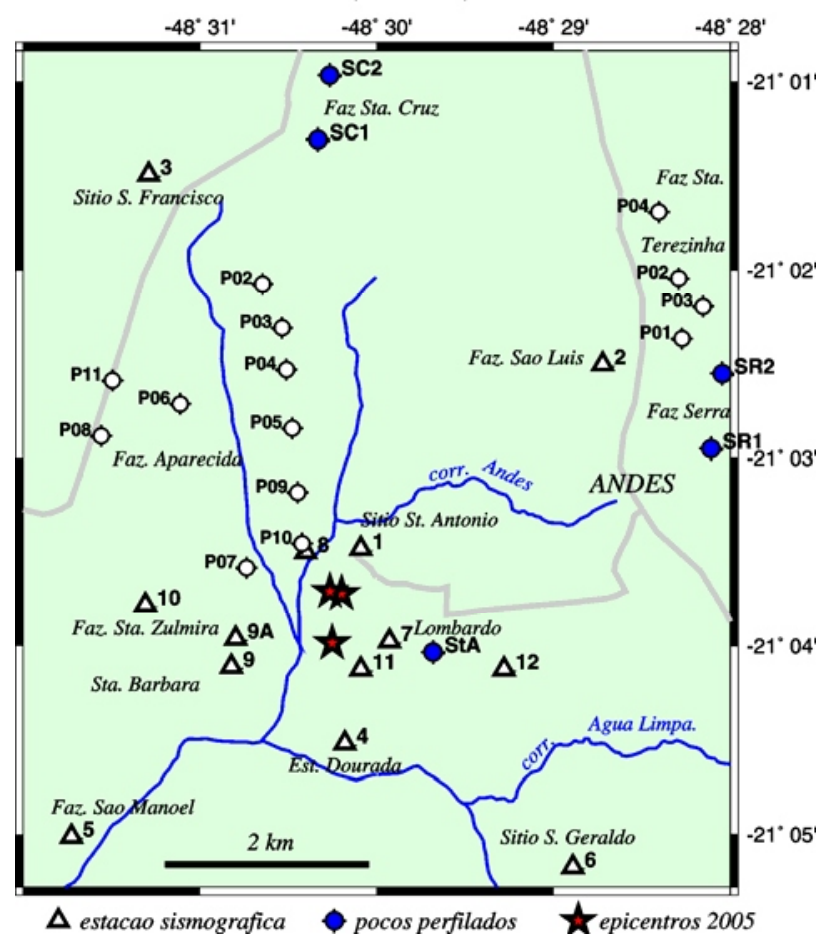

Figura 1. Localização das estações sismográficas (triângulos) instaladas em março de 2005. As estrelas são os epicentros dos três maiores sismos até junho de 2006. Círculos são os poços de Andes que perfuraram a camada de basalto; nos poços em azul foram feitas perfilagens térmicas.

A relação entre sismos e poços foi estabelecida considerando a proximidade dos epicentros, as ocorrências cíclicas dos tremores, tanto relacionadas com a perfuração quanto com 0 bombeamento dos poços, e a tendência de migração dos epicentros para longe dos poços. Um mecanismo 
possível para a indução dos tremores é a comunicação entre o aqüífero superficial e fraturas ou fendas no basalto, possibilitada pela perfuração dos poços. A pressão adicional da água agindo sobre zonas fraturadas, previamente sob esforços críticos, pode ser a causa dos sismos.

\section{Metodologia}

A rede de sismógrafos instalada em março de 2005 vem operando continuamente para acompanhar a atividade sísmica em Andes (Fig. 2). Em junho de 2006 operavam 6 estações indicadas na Fig. 2b.

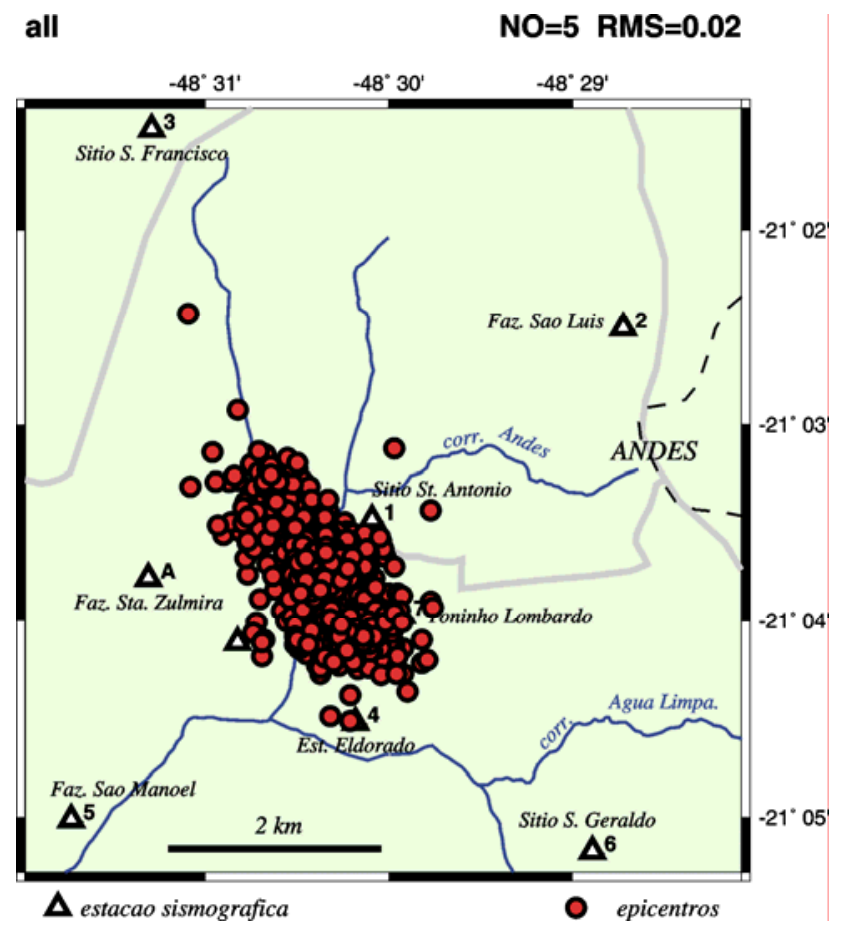

Figura 2a. Epicentros dos tremores de Andes entre 10/03 e 28/06/2005.

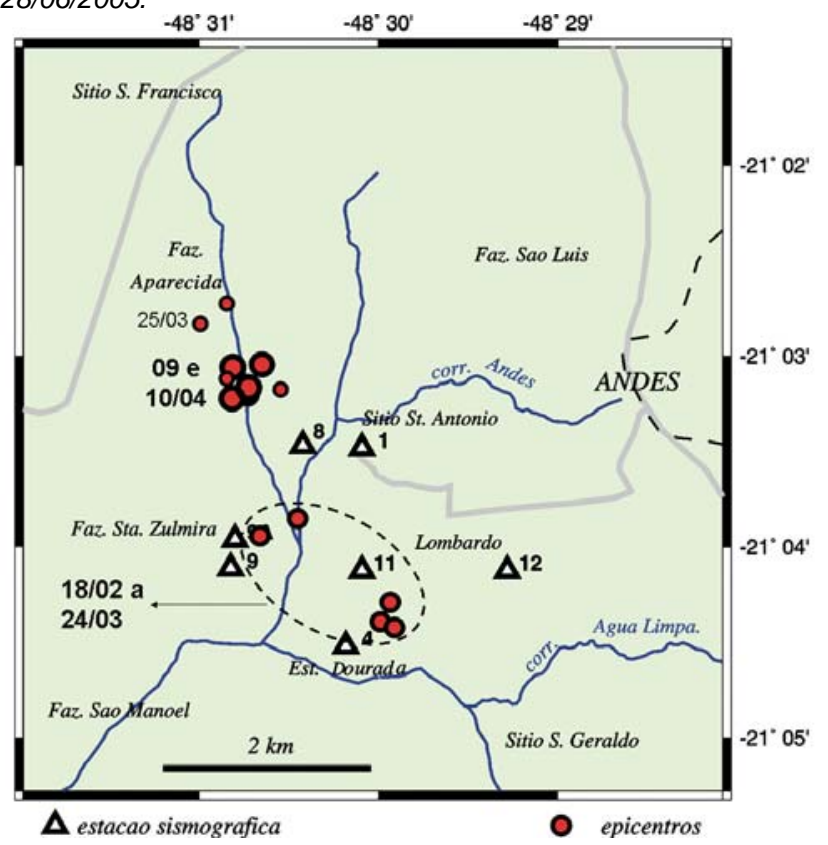

Figura 2b. Epicentros dos sismos de fevereiro a abril de 2006. Os eventos de 18/02 a 24/03 na parte mais ao sul são microtremores não sentidos por moradores. O evento maior de 09/04/2006 com epicentro na Faz. Aparecida foi sentido até Andes.
Cobrem a área sedimentos da Formação Adamantina, com espessuras entre 50 e $100 \mathrm{~m}$, e o basalto da Formação Serra Geral. A espessura do basalto estimada para esta região é da ordem de $500 \mathrm{~m}$. Para localização dos sismos, foi usado um modelo de velocidades com uma camada de arenito (espessura de $70 \mathrm{~m}$ e velocidade $P$ de $2,5 \mathrm{~km} / \mathrm{s}$ ) e uma de basalto com velocidade $P$ de $5,0 \mathrm{~km} / \mathrm{s}$. Foram usadas correções de estação para compensar espessuras diferentes da camada de arenito. A melhor relação $\mathrm{Vp} / \mathrm{Vs}$ determinada com o diagrama de Wadati deu um valor de 1,80 .

Hipocentros são determinados com pelo menos três estações e cinco leituras das ondas $\mathrm{P}$ e $\mathrm{S}$. A precisão é da ordem de $200 \mathrm{~m}$ no epicentro e 200 a $500 \mathrm{~m}$ na profundidade. Apesar da maior incerteza nas profundidades, é possível verificar que os tremores se originam na camada de basalto.

\section{DIscussão}

O primeiro enxame de eventos ocorreu de janeiro a julho de 2004 sendo sentido pelos moradores mas sem registro instrumental. Entre agosto e dezembro de 2004 não foram sentidos tremores em Andes; este período coincide com a época de bombeamento contínuo dos poços para irrigação. O segundo enxame começou a ser sentido em dezembro de 2004, teve um pico de atividade em março e abril de 2005, e diminuiu bastante depois de agosto de 2005 (Assumpção \& Yamabe, 2005). A rede sismográfica instalada no início de março de 2005 mostrou que os epicentros (Fig. 2a) estavam nas proximidades de poços tubulares de $120-220 \mathrm{~m}$ de profundidade, perfurados em 2003 e 2004 (poços P02 a P10 e StA na Fig. 1) que exploram água das fraturas do basalto. $A$ Fig. 2a mostra a localização da área epicentral deste segundo surto de atividade sísmica.

Além da proximidade dos epicentros aos poços com vazão extremamente grande (P07 e P10), durante o surto de 2005 notou-se uma tendência de migração dos epicentros para distâncias maiores com relação àqueles poços. A Fig. 3 (página 4) mostra esta distância para todos os epicentros bem determinados desde 10/03/2005 (instalação da rede sismográfica) até 10/04/2006. Pode-se perceber uma tendência das distâncias máximas aumentarem até agosto de 2005. Considerando que naquela época os poços da Faz. Aparecida não estavam sendo bombeados, essa migração pode ser interpretada como um mecanismo de difusão da pressão de poro adicional, causada pela água proveniente do arenito superior. A linha grossa na Fig. 3 indica a variação temporal da pressão de poro com uma difusividade hidráulica de $0,3 \mathrm{~m}^{2} / \mathrm{s}$, iniciandose em meados de dezembro de 2004 quando os poços cessaram o bombeamento. Esta difusividade "sísmica" é compatível com valores encontrados em casos de sismicidade induzida por barragens e por injeção de fluidos em poços profundos.

Depois de agosto de 2005, provavelmente com nova fase de bombeamento dos poços para irrigação contínua, a atividade sísmica diminuiu bastante, com apenas alguns micro-tremores por mês registrados pela rede sismográfica. Esta diminuição da atividade sísmica pode ter sido causada pela queda da pressão de poro do aquífero fraturado devido ao bombeamento dos poços. A diminuição da pressão da 
água em fraturas sismogênicas no basalto aumenta o atrito nos blocos de basalto dificultando a ocorrência de deslocamentos sísmicos.

Um novo surto de atividade iniciou-se com alguns micro-tremores nos dias 23-25/03 de 2006. No dia 09/04/06 os tremores aumentaram em número e intensidade sendo sentidos em várias localidades do distrito de Andes. A Fig. $2 b$ mostra alguns dos epicentros deste terceiro surto de atividade localizado dentro da Fazenda Aparecida. O pico de atividade ocorreu em 09 e 10 de abril (magnitude até 1,5 na escala Richter) quando foram registrados mais de uma centena de tremores. Quatro novos poços haviam sido perfurados um mês antes nas proximidades dos epicentros.

Foram feitas perfilagens térmicas em seis poços profundos da região: cinco de Andes (indicados na Fig. 1) e um em Monte Azul Paulista. As medidas de temperatura em cinco poços do distrito de Andes e um no município vizinho de Monte Azul Paulista, mostraram movimentos descendentes de água dentro do poço, indicando a existência da referida comunicação entre o aqüífero superficial e as fraturas do basalto (Yamabe et al., neste Simpósio). A água desce pelos poços geralmente entre as profundidades de 40 e 130m. Em quatro dos poços perfilados em Andes é possível, inclusive, ouvir o som de queda d'água, indicando que a água entra continuamente para dentro do poço vinda da camada de arenito e, portanto, deve sair do poço em alguma profundidade mais abaixo. Ou seja, os poços estão transferindo água das camadas superiores de arenito para prováveis fraturas ou aqüíferos no basalto em profundidades maiores.

É provável que a maioria dos poços perfurados no basalto naquela região apresente esta característica. Inclusive, um levantamento dos poços mais rasos, que exploram o arenito Adamantina, mostrou que estes quando perfurados até o topo do basalto, apresentam também essa movimentação vertical de água dentro do poço.

\section{Conclusão}

Considerando que a porosidade e a permeabilidade de um aqüífero fissural dependem da distribuição, abertura, e tamanho das fissuras do basalto (Feitosa e Manoel $\mathrm{F}^{\circ}, 2000$ ), é possível inferir que poços tubulares com vazões tão altas como as observadas (150-190 m³/h, poços P10 e P07) (ver Fig. 1), sejam indicativos de alta concentração de fraturas ou fendas no basalto na área epicentral.

Concentração de fraturas poderia ser indício de que a rocha esteve previamente sujeita a grandes esforços e a perfuração de poços, permitindo a comunicação de aqüíferos superiores com a zona fraturada do basalto, pode ter facilitado os deslocamentos sísmicos, através da pressão adicional da água do arenito.

Quando os poços são bombeados, ao contrário, a água é retirada das fraturas e a pressão de poro nas falhas diminui. Portanto, explica-se a relação entre atividade sísmica com os índices pluviométricos da região, que determinam a quantidade de água bombeada dos poços tubulares, especialmente daqueles utilizados para irrigação.

O terceiro ciclo de atividade de março e abril de 2006 confirma a sazonalidade da atividade sísmica em Andes, com maior intensidade no primeiro semestre de cada ano. Além disso, a perfuração de novos poços em 2006 e a localização dos epicentros deste novo ciclo de atividade na proximidade desses novos poços, são fortes argumentos para relacionar os poços tubulares que exploram aqüífero de fraturas com os tremores de terra em Andes.

Outros casos anteriores de tremores induzidos pela abertura de poços tubulares foram constatados em Nuporanga (Yamabe \& Hamza, 1996) e em Presidente Prudente (Yamabe, 1999), ambos na Bacia do Paraná onde ocorrem basaltos da Formação Serra Geral. O caso de Bebedouro indica que a probabilidade de poços tubulares profundos provocarem sismos pode ser maior do que se suspeitava.

\section{Agradecimentos}

Agradecemos à Prefeitura Municipal de Bebedouro pelo apoio aos trabalhos de campo, ao DAEE de São Paulo e Araraquara pela colaboração e acesso ao arquivo de dados, ao Prof. Chang (UNESP/Rio Claro) pela análise de água, ao Prof. Dourado (UNESP/Rio Claro) pelas informações sobre os sismos registrados, ao Prof. Ricardo Hirata (IGc/USP) pelas profícuas discussões, aos proprietários dos sítios onde as perfilagens térmicas foram realizadas, e à população em geral do Distrito de Andes. Especial agradecimento aos proprietários do Sítio Santo Antonio, José e Didier Cagnin, pelo apoio fundamental aos trabalhos de campo. A rede sismográfica foi instalada com apoio de Luis Galhardo, Dênis Schramm e Célia Fernandes.

\section{Referências}

Assumpção, M. 2006. Os novos tremores de terra de abril/2006 em Bebedouro, distrito de Andes. (Relatório não publicado: www.iag.usp.br/ marcelo/bebedouro)

Assumpção, M. \& Yamabe, T.H. 2005. Atividade sísmica no Distrito de Andes, Bebedouro, e a possível relação com perfuração de poços tubulares. (Relatório não publicado: www.iag.usp.br/ marcelo/bebedouro )

Feitosa, F.A.C. \& Manoel $\mathrm{F}^{\circ}$, J. (Coords.), 2000. Hidrogeologia - Conceitos e Aplicações. $2^{\mathrm{a}}$ ed., CPRM/REFO, LABHID-UFPE, Fortaleza, Brasil.

Yamabe, T.H., 1999. Estudos geofísicos para explicar a sismicidade induzida e orientar a exploração de água subterrânea em Nuporanga-SP. Tese de Doutorado, Instituto de Astronomia, Geofísica e Ciências Atmosféricas, USP, São Paulo.

Yamabe, T.H. \& Hamza, V.M., 1996. Geothermal Investigation in an area of induced seismic activity, Northern São Paulo State, Brazil. Tectonophysics, 253, 209-225. 


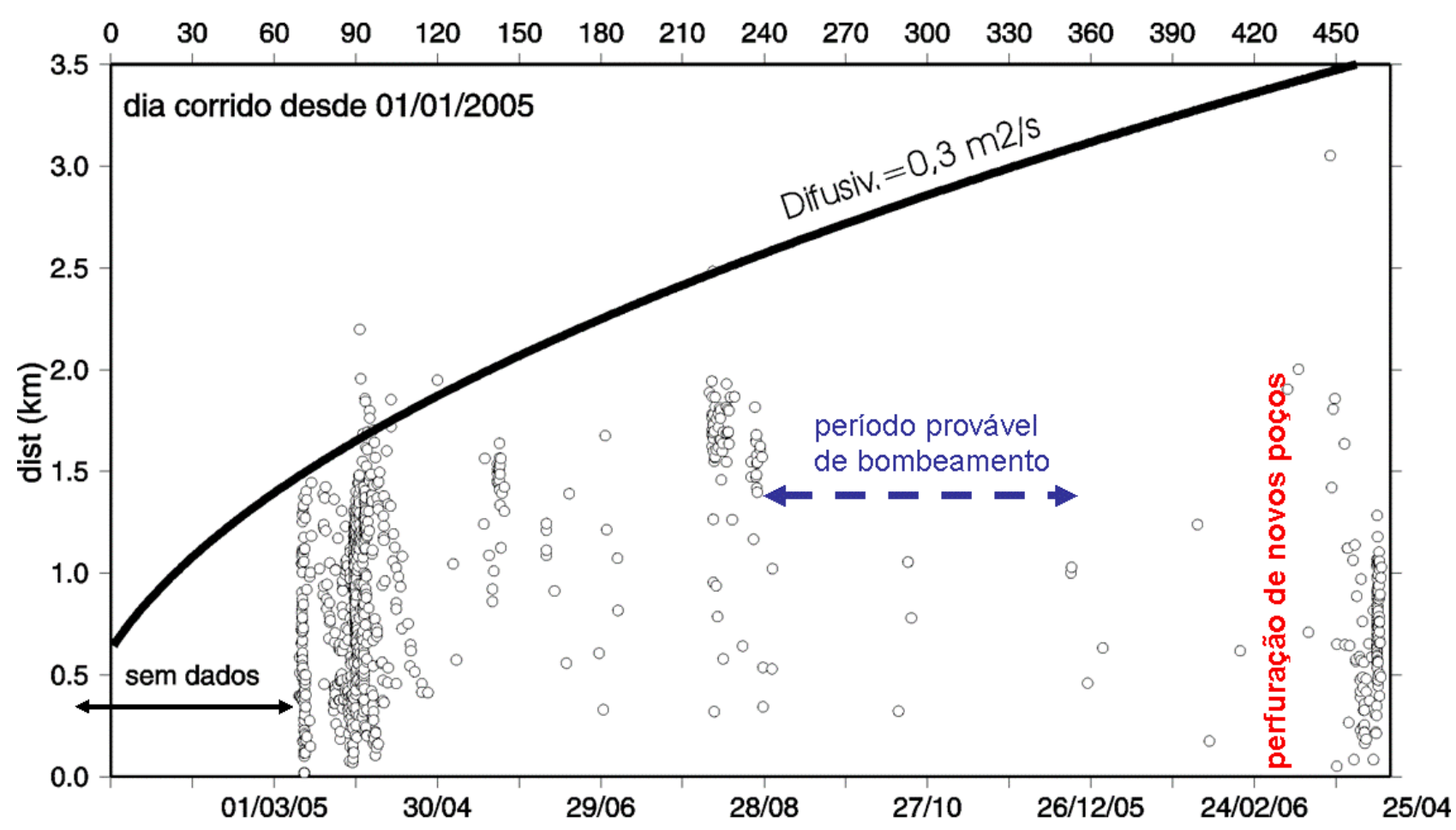

Fig. 3. Evolução temporal da atividade sísmica registrada pela rede sismográfica e a distância (km) de cada epicentro ao ponto médio entre os poços P07 e P10. A linha preta grossa descreve a distância, para uma dada pressão de poro, característica de uma difusividade hidráulica de $0,3 \mathrm{~m}^{2} / \mathrm{s}$, a partir de meados de dezembro de 2004 quando os poços da Faz. Aparecida pararam o bombeamento contínuo durante a estiagem. Note uma tendência das distâncias epicentrais máximas aumentarem com o tempo. No segundo semestre de 2005 os poços voltaram a ser bombeados, mas as datas exatas de início e térmico não são conhecidas. No final de fevereiro ou março de 2006, quatro novos poços foram perfurados iniciando nova onda de tremores. 